\title{
EVALUATION OF PATIENTS' SATISFACTION AFTER RHINOPLASTY: A PROSPECTIVE STUDY
}

\author{
By \\ Abd El-Rahman Awadeen \\ Department of Plastic and Reconstructive Surgery, Faculty of Medicine, Al-Azhar \\ University, Cairo, Egypt \\ Corresponding author: Abd El-Rahman Awadeen, \\ Mobile: 01001110592, E-mail: abdelrahmanawadeen.206@ azhar.edu.eg
}

\begin{abstract}
Background: Rhinoplasty is a technically demanding procedure, requiring a comprehensive understanding of the nasal and facial anatomy and carrying out the nasofacial analysis. These factors are critical in determining the operative plan and the most effective technique that manipulates cartilage, bone, and soft tissue. The ultimate aim of rhinoplasty is to satisfy the patients with post-operative aesthetic and functional outcomes.
\end{abstract}

Objective: To assess the long-term functional and aesthetic satisfaction among a sample of Egyptian patients subjected to rhinoplasty.

Patients and Methods: This was a prospective cohort study conducted at Al-Azhar University Hospitals from May 2014 to May 2019. Patients aged more than 22 years of both sexes subjected to rhinoplasty, and presented in the outpatient clinics for follow-up were included. Post-operative counseling with the patients about the pre-operative conditions and deformities was done. Patients' satisfaction was assessed using the rhinoplasty outcome evaluation questionnaire.

Results: This study included a total of 30 patients. Of them, there was $3(10 \%)$ male and 27 (90\%) females with a mean age of 38.1 \pm 6 .91years. The mean level of Rhinoplasty outcome evaluation questionnaire was 77.1 \pm 6.91 . Out of the included patients, $17(56.66 \%)$ patients were satisfied with their aesthetic and functional rhinoplasty outcomes and were presented only for follow-up. Of the remaining 13 (43.33\%) cases, four $(13.3 \%)$ cases required secondary correction due to functional problems and complained of headache and difficulty breathing. Two patients were dissatisfied due to partner dissatisfaction that developed significant psychological impact.

Conclusion: A considerable proportion of patients were dissatisfied after rhinoplasty. The major contributing factors are related to functional and aesthetic problems, as well as psychological morbidities. Therefore, patients seeking rhinoplasty should be subjected to thoroughly functional and psychological evaluation preoperatively to achieve the desired functional and aesthetic outcomes.

Keywords: Rhinoplasty, satisfaction, aesthetic, functional.

\section{INTRODUCTION}

Rhinoplasty is considered one of the most predominant plastic surgery interventions. Whereas the face is the most crucial part of the body, the nose represents the most prominent facial feature with a significant impact on facial identity. Recently, the number of rhinoplasty procedures has been increasing dramatically (Balai et al., 2021). This is because of the noticeable advances in surgical technology and the messages delivered by social media concerning beauty. Rhinoplasty is a 
technically demanding procedure, requiring a comprehensive understanding of the nasal and facial anatomy and carrying out the nasofacial analysis. These factors are critical in determining the operative plan and the most effective technique that manipulates cartilage, bone, and soft tissue ( Rohrich Ahmad, 2011 and Naraghi \& Atari, 2015.

The ultimate aim of rhinoplasty is to satisfy the patients with post-operative aesthetic and functional outcomes. Patients are seeking rhinoplasty desire a fundamental change in their face, highlighting how closely their personality and self-esteem are related to rhinoplasty (Muslu and Demir, 2019). Patients' satisfaction varied considerably based on age, gender, education level, ethnicity, culture, and expectation level. However, studying satisfaction in rhinoplasty represents a neglected area of research; with a limited number of studies evaluate it (Yang et al., 2018). Such knowledge is critical for pre-operative recognition of patients at higher risk of being dissatisfied regarding their rhinoplasty post-operative outcomes. This will help plastic surgeons to subject patients at risk to pre-operative psychiatric consultation and psychotherapy.

This study aimed to reveal the longterm functional and aesthetic satisfaction among a sample of Egyptian patients subjected to rhinoplasty.

\section{PATIENTS AND METHODS}

This prospective cohort study was carried out at Al-Azhar University Hospitals from May 2014 to May 2019. The nature of the study was clearly demonstrated to all participants with respect to the Declaration of Helsinki. The included patients assigned informed consents prior to the study proceeding.

Patients aged more than 22 years of both sexes subjected to rhinoplasty and presented in the outpatient clinics for follow-up were included. Patients with nasal cleft deformity, craniofacial clefts, or other congenital nasal deformities were ousted. Digital photography was performed for all patients to record postoperative outcomes. This study aimed to prospectively evaluate the satisfaction outcomes of patients subjected to rhinoplasty and presented postoperatively in the outpatient clinic for follow-up. Therefore, post-operative counseling with the patients about the pre-operative conditions and deformities was done, and the availability of any previous figures was considered.

Clinical evaluation of the aesthetic and functional outcomes, including anthropometric measurements of the nose and face, was considered. The assessment includedanthropometric measurements of the nose; the frontonasal angle, tipcolumellar angle, lip-columellar angle, and the naso-facial angle at the anterior view. The length and continuity (straitening) of the dorsum of the nose were assessed, in addition to width of the alar base and equality between both nostril openings and its shape in basal view. Assessment of the tip definition and columellar show was evaluated. In the lateral profile view,tip projection and rotation, and supratip valley were evaluated.

Analysis of nasal dimensions in relation to anthropometric measures of the face to assess the naso-facial harmony was 
done. In the cephalocaudal view, the cheek mound, circumorbital area, nasal height, and allar flare were assessed. In the lateral profile view, the harmony of the nose in relation to both lips and chin was assessed. Functional evaluation of the airway by ENT examination and endoscopic assessment was performed. A detailed discussion with the patient was done about their satisfaction for results and the impact of surgery on the psychological and social relationships. Additionally, the partner or relative satisfaction and their acceptance for the results without making the nose as a point of interest was considered.

Patients' satisfaction was assessed using the Rhinoplasty outcome evaluation (ROE) questionnaire (Izu et al., 2012).It is a standardized tool for evaluating the quality-of-life following rhinoplasty. This tool is composed of six questions that evaluate patients' physical, social, and emotional status. The questioner component was explained and discussed with all patients. It was filled at least six months post-operatively in all patients (Table 1).

Table (1): Rhinoplasty outcome evaluation (ROE) questionnaire

\begin{tabular}{|c|l|c|c|c|c|c|}
\hline 1 & $\begin{array}{l}\text { How much do you like the appearance of your } \\
\text { nose? }\end{array}$ & $\begin{array}{c}0 \\
\text { (No) }\end{array}$ & 1 & 2 & 3 & $\begin{array}{c}4 \\
\text { (Yes) }\end{array}$ \\
\hline 2 & How much can you breathe through your nose? & $\begin{array}{c}0 \\
\text { (Not at all) }\end{array}$ & 1 & 2 & 3 & $\begin{array}{c}4 \\
\text { (Very well) }\end{array}$ \\
\hline 3 & $\begin{array}{l}\text { How much do you think your friends and close } \\
\text { ones like your nose? }\end{array}$ & $\begin{array}{c}0 \\
\text { (Not at all) }\end{array}$ & 1 & 2 & 3 & $\begin{array}{c}4 \\
\text { (Always) }\end{array}$ \\
\hline 4 & $\begin{array}{l}\text { Do you think your current nasal appearance } \\
\text { limits your social or professional activities? }\end{array}$ & $\begin{array}{c}0 \\
\text { (Always) }\end{array}$ & 1 & 2 & 3 & $\begin{array}{c}4 \\
\text { (Never) }\end{array}$ \\
\hline 5 & $\begin{array}{l}\text { How confident are you that your nasal } \\
\text { appearance is the best it can be? }\end{array}$ & $\begin{array}{c}0 \\
\text { (Not at all) }\end{array}$ & 1 & 2 & 3 & $\begin{array}{c}4 \\
\text { (Yes) }\end{array}$ \\
\hline 6 & $\begin{array}{l}\text { Would you like to surgically alter the } \\
\text { appearance or function of your nose? }\end{array}$ & $\begin{array}{c}0 \\
\text { (Absolutely) }\end{array}$ & 1 & 2 & 3 & $\begin{array}{c}4 \\
\text { (No) }\end{array}$ \\
\hline
\end{tabular}

Statistical analysis: Continuous normally distributed data were reported using mean and standard deviation (SD). Categorical variables were expressed using number and percentage. Statistical analysis was performed using SPSS software version 25 for Windows (SPSS Inc., Chicago, IL, USA).

\section{RESULTS}

This study included a total of 30 patients. Of them, there was $3(10 \%)$ male and $27(90 \%)$ females with a mean age of $38.1 \pm 6.91$ years. The mean level of rhinoplasty outcome evaluation questionnaire was $3.4 \pm 0.8$. Out of the included patients, $17(56.66 \%)$ patients were satisfied with their aesthetic and functional rhinoplasty outcomes and were presented only for follow-up. Of the remaining $13(43.33 \%)$ cases, four $(13.3 \%)$ cases required secondary correction due to functional problems and complained of headache and difficulty breathing. By examination, they had internasal synechia with asymmetry of nostrils, inspiratory collapse, residual septal deviation, and residual bone spare 
in the bony septum, respectively. Two cases were realistically dissatisfied regarding the aesthetic outcome due to illdefined cheeks. Three cases need secondary correction to restore tip definition, correct columellar show and restore dorsal contouring (Table 2).

Table (2): Patients demographic characteristics

\begin{tabular}{|c|c|}
\hline Variables $\quad$ Results & Mean/SD or Number (\%) \\
\hline Age & $38.1 \pm 6.91$ \\
\hline \multicolumn{2}{|l|}{ Gender } \\
\hline Female & $27(90 \%)$ \\
\hline Male & $3(10 \%)$ \\
\hline
\end{tabular}

Two patients were dissatisfied due to partner dissatisfaction who developed a significant psychological impact. This burden was related to continuous psychological pressure of the partner by critiquing the nose appearance and considering the rhinoplasty as an insult. By counseling with the partners, disclosure of preoperative resistance to be subjected to the operation and these female cases were subjected to rhinoplasty without notifying their husbands. This state initiates virulent behavior from the husband toward them, stimulating a sense of guilt that disrupts patient satisfaction.
Both patients and their husbands were referred to psychiatric consultation and responded after three months of sessions. Another male case with the obsessivecompulsive disorder, which has been manifested clinically post-operatively, and referred to a psychiatrist. Another dis satisfied case despite good aesthetic results was reported due to the family's repeated criticism and sarcastic behavior. She was thirty years old and still single, creating a psychic load and transforming the nose as a nidus for obsession. She was referred for psychiatric evaluation (Table 3 and Figures 1, 2, 3, and 4).

Table (3): Satisfaction outcomes after rhinoplasty

\begin{tabular}{|c|c|}
\hline Variables Results & Number (\%) \\
\hline Satisfied cases & $17(56.66 \%)$ \\
\hline Dissatisfied cases & $13(43.33 \%)$ \\
\hline Functional problems & $4(13.3 \%)$ \\
\hline Ill-defined cheeks & $2(6.66 \%)$ \\
\hline Aesthetic problems & $3(10 \%)$ \\
\hline Partner dissatisfaction & $2(6.66 \%)$ \\
\hline Obsessive-compulsive disorder & $1(3.3 \%)$ \\
\hline Family dissatisfaction & $1(3.3 \%)$ \\
\hline
\end{tabular}




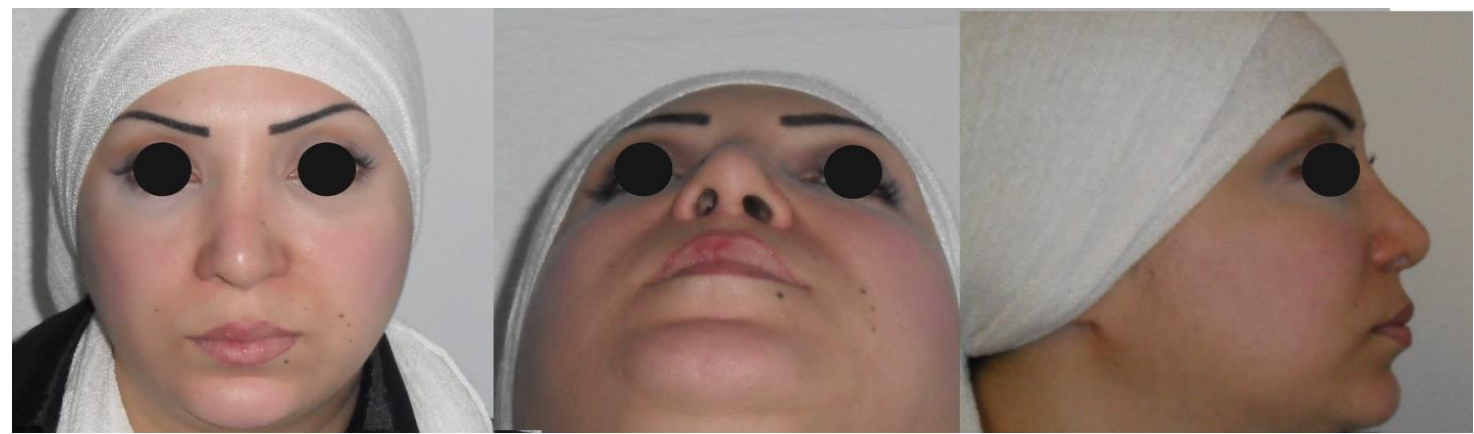

Figure (1): Anterior, basal, and lateral view of a female face dissatisfied of rhinoplasty due to intranasal synechia with nostril asymmetry despite the good aesthetic outcomes

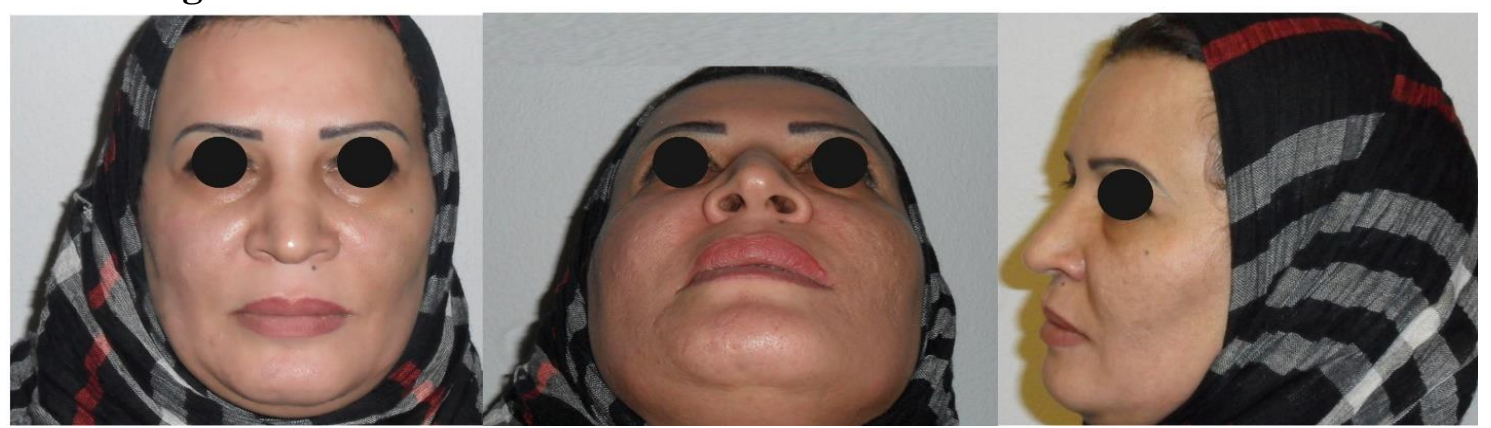

Figure (2): Anterior, basal, and lateral view of a female face dissatisfied of rhinoplasty due to loss of nasofacial harmony due to deficient cheeks and tear troughs

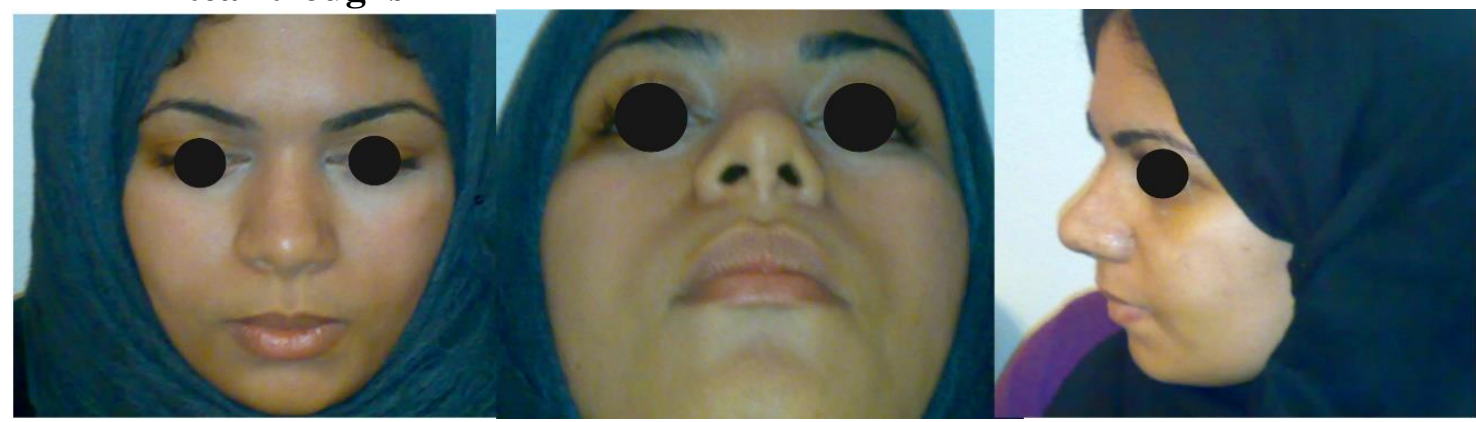

Figure (3): Anterior, basal, and lateral view of a female face dissatisfied of rhinoplasty due to family criticism despite good aesthetic and functional outcomes
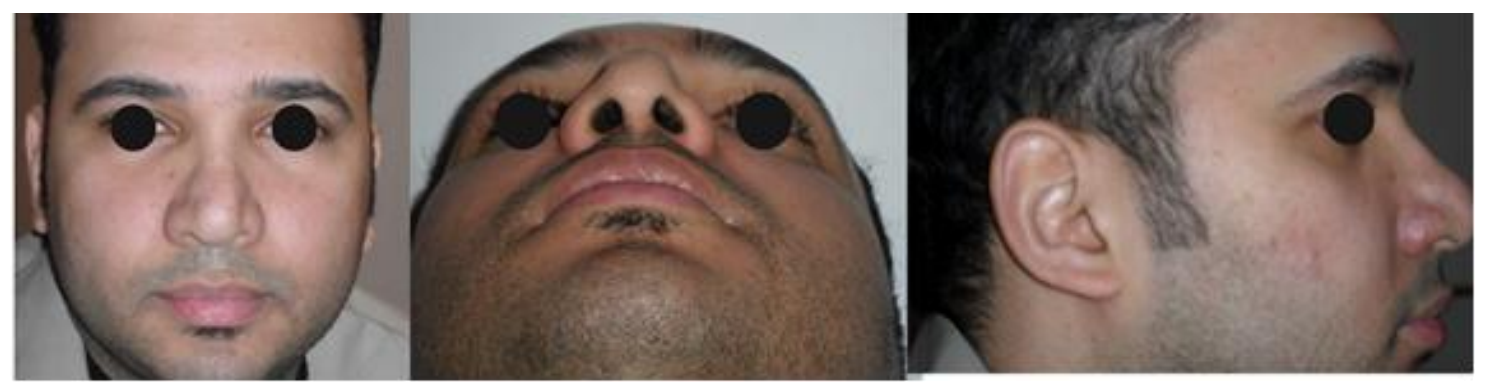

Figure (4): Anterior, and lateral view of a male face dissatisfied of rhinoplasty due to obsessive compulsive disorder despite good aesthetic and functional outcomes. 


\section{DISCUSSION}

In rhinoplasty, a comprehensive understanding of patients' concerns and desires is paramount to accomplish patient satisfaction. Therefore, it is extremely crucial to determine why patients seek rhinoplasty. Additionally, patients should be aware of realistic and unrealistic expectations related to rhinoplasty aesthetic outcomes. Rhinoplasty is aimed to restore the youthful appearance of the nose and improve patient's quality of life. Although the technical aspect of the rhinoplasty is challenging, patient satisfaction is the parameter that detects the intervention's success (Chauhan et al., 2011; Izu et al., 2014 and Xiao et al., 2019).

The literature is still limited regarding the assessment of satisfaction rates after rhinoplasty. The evidence obtained in this study revealed that approximately four of every ten patients who received rhinoplasty were dissatisfied regarding their outcomes six months after surgery. The primary cause of this dissatisfaction was functional or aesthetic problem necessitate secondary correction. Furthermore, the psychological background of rhinoplasty seekers or their relatives was associated with dissatisfaction. The dissatisfaction rate in this study was relatively high, relative to Khansa et al. (2016) who reported a dissatisfaction rate of $16.7 \%$. They reported that female patients were more vulnerable to verbalizing a functional or morphological reason for their dissatisfaction despite the good surgical results. In this concern, Khan et al. (2019) reported a similar mean level of ROS six months after the surgery.
Several factors contribute to dissatisfaction after rhinoplasty. This includes elderly patients, patients receiving antidepressants, high alcohol consumption, poor social relationships, and body dysmorphic disorder (Picavet et al., 2013; AlHarethy et al., 2017 and Herruer et al., 2018). In Egypt, a study conducted by Omar et al. (2019) reported a depression rate of more than $50 \%$ among rhinoplasty seekers. In this respect, the most predominant category with psychiatric morbidity was non-marid females who performed previous cosmetic operations and had psychiatric illnesses. Therefore, rhinoplasty seekers should be subjected to thoroughly evaluation for psychological disabilities before surgery to avoid possible dissatisfaction not related to the intervention (Ziglinas et al., 2014).

\section{CONCLUSION}

A considerable proportion of patients were dissatisfied after rhinoplasty. The major contributing factors are related to functional and aesthetic problems, as well as psychological morbidities. Therefore, patients seeking rhinoplasty should be subjected to thoroughly functional and psychological evaluation preoperatively to achieve the desired functional and aesthetic outcomes.

\section{REFERENCES}

1. AlHarethy, S., Al-Angari, S., Syouri, F., Islam, T. and Jang, Y. (2017): Assessment of satisfaction based on age and gender in functional and aesthetic rhinoplasty.European Archives of Oto-Rhino-Laryngology, 274(7): 2809-2812.

2. Balai, E., Jolly, K., Bhamra, N., Osborne, M. S. and Barraclough, J. (2021): The changing face of rhinology in the NHS: a study of septoplasty, septorhinoplasty and 
rhinoplasty hospital episode statistics. The Annals of the Royal College of Surgeons of England, 103(4): 291-295.

3. Chauhan, N., Alexander, J., Sepehr, A. and Adamson, P. (2011): Patient complaints with primary versus revision rhinoplasty: analysis and practice implications.Aethetic Surgery Journal, 31(7): 775-780.

4. Herruer, J., Prins, J., van Heerbeek, N., Verhage-Damen, G. and Ingels, K. (2018): Does self-consciousness of appearance influence postoperative satisfaction in rhinoplasty?. Journal of Plastic, Reconstructive and Aethetic Surgery, 71(1): 79-84.

5. Izu, S., Kosugi, E., Brandão, K., Lopes, A., Garcia, L., Suguri, V.and Gregório, L. (2012): Normal values for the Rhinoplasty Outcome Evaluation (ROE) questionnaire. Brazilian Journal of Otorhinolaryngology, 78(4): 76-79.

6. Izu, S., Kosugi, E., Lopes, A., Brandão, K., Sousa, L., Suguri, V. and Gregório, L. (2014): Validation of the rhinoplasty outcomes evaluation (ROE) questionnaire adapted to Brazilian Portuguese. Quality of Life Research, 23(3), 953-958.

7. Khan, N., Rashid, M., Khan, I., Sarwar, S., Rashid, H., Khurshid, M. and Fatima, N. (2019): Satisfaction in patients after rhinoplasty using the rhinoplasty outcome evaluation questionnaire. Cureus, 11(7): e5283.

8. Khansa, I., Khansa, L. and PearsonG. (2016): Patient satisfaction after rhinoplasty: a social media analysis. Aesthetic Surgery Journal, 36(1): NP1-NP5.

9. Muslu, Ü. and Demir, E. (2019): Development of rhinoplasty: yesterday and today. Med Sci, 23(97): 294-301.
10. Naraghi, M. and Atari, M. (2015): A comparison of depression scores between aesthetic and functional rhinoplasty patients. Asian Journal of Psychiatry, 14: 28-30.

11. Omar, A., Eid, M., Ali, R., El Missiry, M., Gawad, A. and El Ghoneimy, S. (2019): Psychiatric morbidity among Egyptian patients seeking rhinoplasty. Middle East Current Psychiatry, 26(1), 1-7.

12. Picavet, V., Gabriëls, L., Grietens, J., Jorissen, M., Prokopakis, E. and Hellings, P. (2013): Preoperative symptoms of body dysmorphic disorder determine postoperative satisfaction and quality of life in aesthetic rhinoplasty. Plastic and Reconstructive Surgery, 131(4): 861-868.

13. Rohrich, R., and Ahmad, J. (2011): Rhinoplasty. Plast Reconstr Surg, 128(2): 49e$73 \mathrm{e}$.

14. Xiao, H., Zhao, Y., Liu, L., Xiao, M., Qiu, W. and Liu, Y.(2019): Functional/aesthetic measures of patient satisfaction after rhinoplasty: a review. Aesthetic Surgery Journal, 39(10): 1057-1062.

15. Yang, F., Liu, Y., Xiao, H., Li, Y., Cun, H. and Zhao, Y. (2018): Evaluation of preoperative and postoperative patient satisfaction and quality of life in patients undergoing rhinoplasty: a systematic review and meta-analysis. Plastic and Reconstructive Surgery, 141(3): 603-611.

16. Ziglinas, P., Menger, D. and Georgalas, $C$. (2014): The body dysmorphic disorder patient: to perform rhinoplasty or not?. European Archives of Oto-RhinoLaryngology, 271(9): 2355-2358. 


\section{تقييم رضا المرضى بعد عملية تجمبل الأنف: در اسة مستقبلية عبد الرحمن عوضين}

قسم جراحة التجميل والحروق، كلية الطب، جامعة الأزهر

E-mail: abdelrahmanawadeen.206@azhar.edu.eg

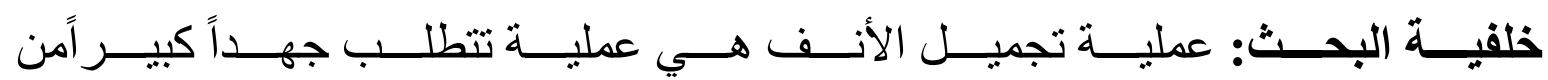

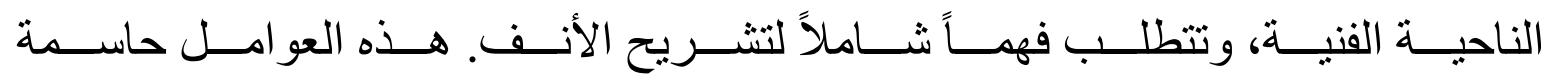

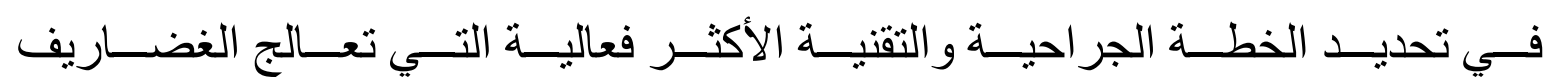

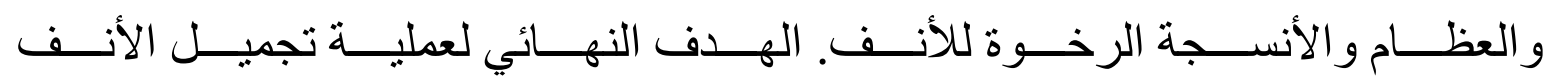
هو إرضاء المرضى بالنتائج الجمالية والوظيفية بعد الجر احة.

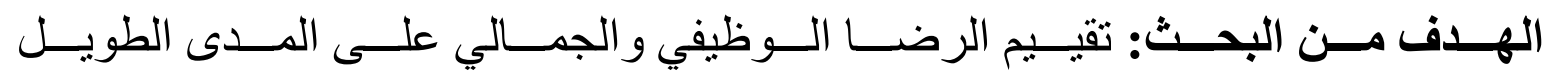

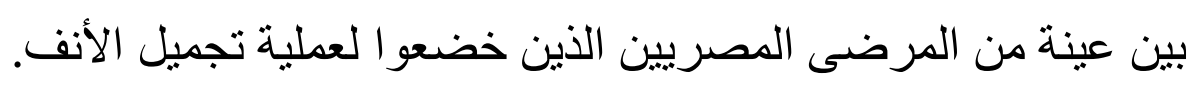

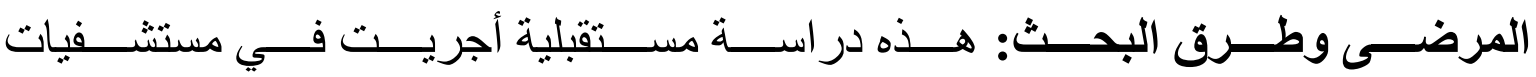

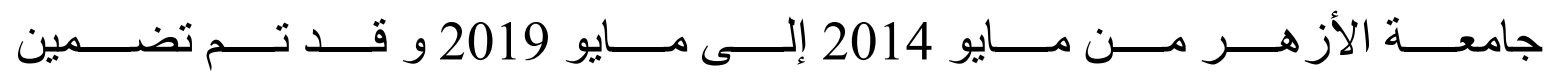

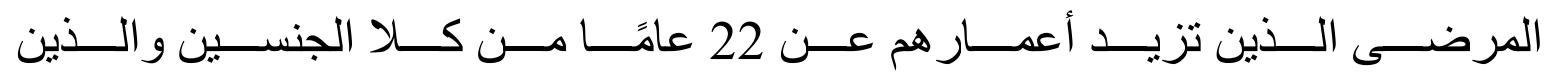

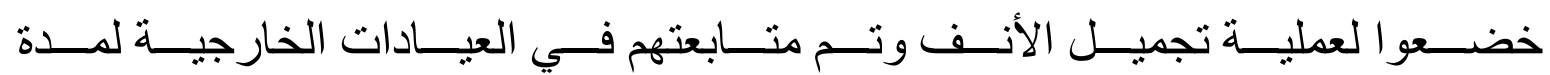

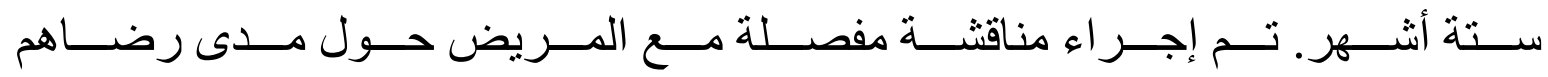

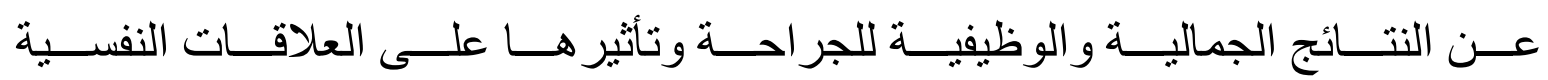

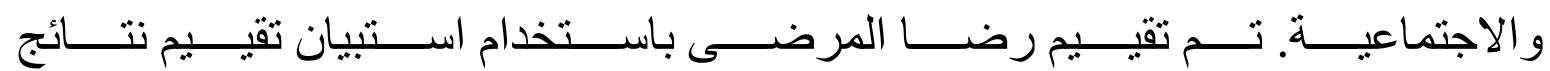
تجميل الأف.

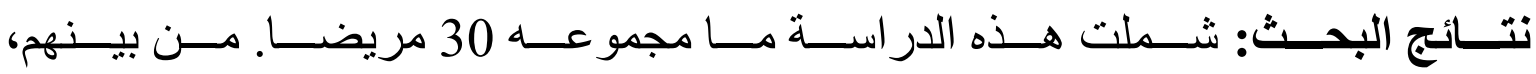

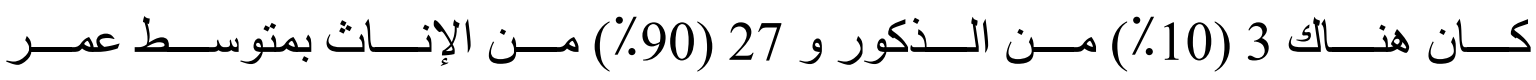

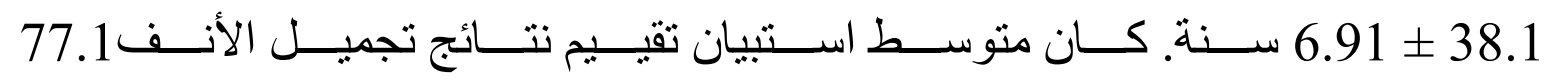

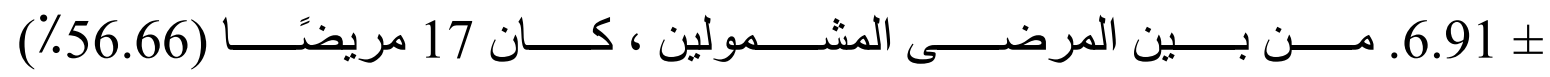


EVALUATION OF PATIENTS' SATISFACTION AFTER RHINOPLASTY... 2441

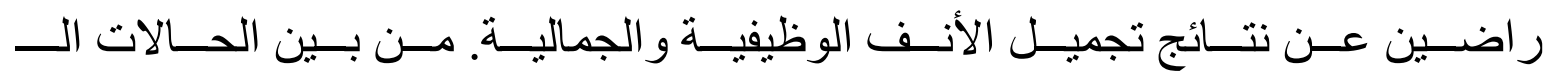

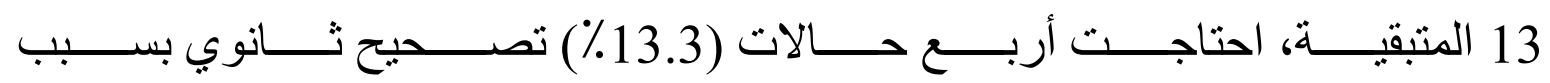

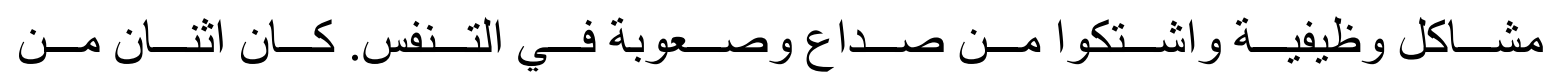

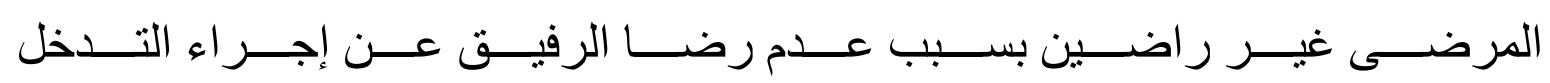
الجمالى للأنف.

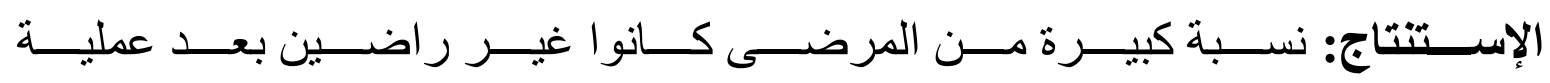

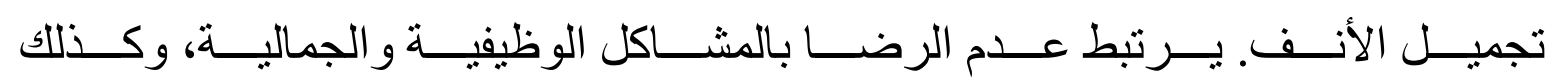

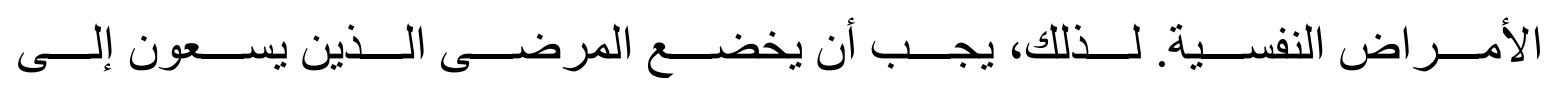

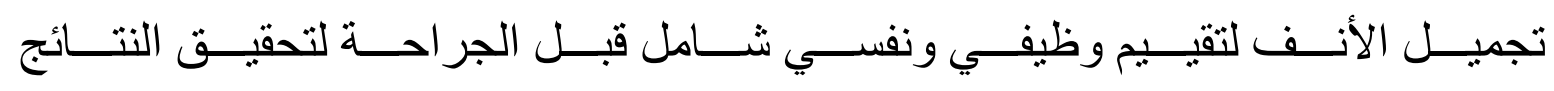
الوظيفية و الجمالية المرجوة.

الكلمات الدالة: تجميل الأنف، الرضا، الجمالية، الوظيفية. 